\title{
Relationships of homophobic bullying during childhood and adolescence with problematic internet and smartphone use in early adulthood among sexual minority men in Taiwan
}

\author{
JIA-IN LEE $1,2, \#$ \\ https://orcid.org/0000-0002-0679-6471 \\ CHENG-FANG YEN1,2,\# \\ RAY C. HSIAO 3 \\ https://orcid.org/0000-0002-6779-0006 \\ HuEI-FAN Hu 4 \\ https://orcid.org/0000-0003-3891-5954
}

'Department of Psychiatry, School of Medicine, College of Medicine, Kaohsiung Medical University, Kaohsiung, Taiwan.

2 Department of Psychiatry, Kaohsiung Medical University Hospital, Kaohsiung, Taiwan.

${ }^{3}$ Department of Psychiatry and Behavioral Sciences, University of Washington School of Medicine, \& Children's Hospital, Seattle, WA.

4 Department of Psychiatry, Tainan Municipal Hospital (managed by Show Chwan Medical Care Corporation), Tainan, Taiwan.

* JI Lee and CF Yen contributed equally to this study.

Received: 10/17/2018 - Accepted: 5/21/2019

DOl: 10.1590/0101-60830000000203

\begin{abstract}
Background: Mental health disparity in sexual minorities is a crucial clinical and public health issue worldwide. A total of 500 homosexual or bisexual men aged between 20 and 25 years participated in this study. Objectives: The aims of the study were to examine the relationships of victimization of traditional and cyber homophobic bullying during childhood and adolescence with problematic internet and smartphone use and activities during early adulthood among sexual minority men in Taiwan. Methods: The seveirities of problematic internet and smartphone use and activities in early adulthood were compared between victims and non-victims of bullying. The severities of problematic internet and smartphone use were also compared among the groups of various types of bullying as well as among the groups of various persistence durations of being bullied. Results: Victims of traditional and cyber homophobic bullying had more severe problematic internet and smartphone use than non-victims. Victims of multi-type bullying had more severe problematic internet use than victims of single-type bullying. Prolonged victimization was significantly associated with problematic internet and smartphone use. Discussion: Victimization of traditional and cyber homophobic bullying during childhood and adolescence predicts problematic internet and smartphone use during early adulthood among sexual minority men.
\end{abstract}

Lee JI et al. / Arch Clin Psychiatry. 2019;46(4):97-102

Keywords: Bullying, homosexuality, bisexuality, internet, smartphone.

\section{Introduction}

Mental health disparity in sexual minorities is a crucial clinical and public health issue worldwide. A meta-analysis of 24 studies revealed that the rates of depression and suicidality were higher among sexual minority youths when compared with heterosexual youths'. The significant relationship between sexual minorities and mental health problems is mainly mediated by negative life experiences, including homophobic bullying due to gender role nonconformity and sexual orientation ${ }^{2}$. Homophobic bullying in childhood and adolescence has a severe effect on future psychosocial and health outcomes in adulthood ${ }^{3}$. Currently, problematic Internet use and smartphone use have become new forms of mental health problems ${ }^{4,5}$. Problematic Internet use has been revealed to be related to depression, anxiety, hostility, interpersonal sensitivity, psychoticism, suicidality, and alcohol abuse ${ }^{4,6}$. Problematic smartphone use was associated with psychological problems such as depression, sleep disturbance, and anxiety ${ }^{5}$, as well as physical discomforts such as neck stiffness, blurred vision, and wrist or back pain ${ }^{4,5}$. Furthermore, heavy mobile phone use can reduce school performance and in-person social interaction ${ }^{4,7}$. However, the relationship between the experience of homophobic bullying victimization in childhood and adolescence and problematic Internet and smartphone use in sexual minority youths has not been examined previously.
Several reasons support the necessity of examining the association of homophobic bullying with problematic Internet and smartphone use among sexual minority individuals. First, according to the minority stress hypothesis, sexual minority individuals experience chronic stress, which is related to a hostile social environment full of stigma, prejudice, and discrimination, and can lead to mental health problems ${ }^{8,9}$. Given that Internet use such as online gaming is one of most common methods that individuals use to cope with stress ${ }^{10,11}$, it is reasonable to hypothesize that sexual minority individuals may engage in Internet and smartphone activities to cope with the stress caused by homophobic bullying, and thus the risks of problematic Internet and smartphone use increase. Second, the development of a coherent self-concept is an important achievement for adolescence ${ }^{12}$. According to the psychological mediation framework ${ }^{13}$, homosexual bullying and internalized stigma may hinder sexual minority youths from developing positive self-concepts ${ }^{12}$. Research indicated that adolescents may develop their sense of self in the era of the Internet and role-playing fantasy games ${ }^{14}$. Victims of homophobic bullying may use the Internet and smartphones as a method to ease their negative emotions. Therefore, it is hypothesized that problematic Internet and smartphone use may develop in the process of trying to develop self-concepts and relieve negative emotions among sexual minority youths due to experiencing homophobic bullying victimization. Third, according to the ecological system model, 
homophobic bullying is the maltreatment of environmental systems toward sexual minority individuals ${ }^{15}$. Nevertheless, sexual minority victims of homophobic bullying may search for social support from the Internet.

No study has examined the effects of multitype and prolonged homophobic bullying on problematic Internet and smartphone use. People may use the Internet and smartphone to perform many types of activities. Whether different types of Internet and smartphone activities are related to homophobic bullying victimization requires further study.

The aims of the present study were to examine the relationships of victimization related to homophobic bullying during childhood and adolescence with problematic Internet and smartphone use and with Internet and smartphone activities during early adulthood among sexual minority men; we also examined the influences of multitype and prolonged homophobic bullying on problematic Internet and smartphone use. We hypothesized that sexual minority men who experienced traditional and cyber homophobic bullying victimization in childhood and adolescence have more severe problematic Internet and smartphone use in early adulthood than those who did not experienced homophobic bullying victimization. Moreover, we hypothesized that those who experienced multitype and prolonged homophobic bullying victimization have more severe problematic Internet and smartphone use than those who experienced single-type and nonpersistent homophobic bullying victimization. We also hypothesized that victims of homophobic bullying engage in different Internet and smartphone activities compared with nonvictims.

\section{Methods}

\section{Participants}

Participants were recruited using an advertisement posted on the Internet, including Facebook, a bulletin board system, and the home page of five health promotion and counseling centers for gay, lesbian, bisexual, and transgender (LGBT) people. We also identified 25 LGBT student clubs in colleges by using "LGBT college student club in Taiwan" as the key words for a Google search and mailed the advertisement to them to recruit the participants. Those who exhibited any influencing factors (e.g., intellectual disability or substance use) that prevented them from understanding the study purpose or completing the questionnaires were excluded. In total, 500 gays or bisexual men aged between 20 and 25 were recruited for this study during the period between September 2015 and December 2016. Informed consent was obtained from all participants prior to assessment. The study was approved by the Institutional Review Board of Kaohsiung Medical University Hospital.

\section{Measures}

\section{Chinese version of the School Bullying Experience Questionnaire}

We used six items from the self-reported Chinese version of the School Bullying Experience Questionnaire (C-SBEQ) to evaluate participants' experience of traditional bullying victimization (including social exclusion; being called a derogatory nickname; being spoken ill of; being beaten up; being forced to do work; and having money, school supplies, and snacks taken away) due to gender nonconformity or sexual orientation during childhood and adolescence. These six items were answered through a 4-point Likert scale, with 0 indicating "never," 1 indicating "just a little," 2 indicating "often," and 3 indicating "all the time"16. Participants who answered 2 or 3 on any item were identified as self-reported victims of traditional bullying. Participants who had experienced traditional bullying victimization were further asked whether bullying victimization occurred during the period of studying in primary school (6-11 years old), junior high school (12-15 years old), or senior high school (16-18 years old), as well as whether bullying victimization occurred at school, at after-school class, tutoring school, and part-time work places. The results of a previous study examining the psychometrics of the C-SBEQ have been described elsewhere and confirmed that the C-SBEQ has adequate reliability and validity ${ }^{16}$. The Cronbach's a values of the scale for measuring traditional bullying victimization due to gender nonconformity and sexual orientation were .79 and .82 , respectively.

\section{Cyberbullying Experiences Questionnaire}

We employed three items on the Cyberbullying Experiences Questionnaire to assess participant experiences of cyberbullying victimization due to gender nonconformity or sexual orientation during childhood and adolescence ${ }^{17}$. The three items addressed the experiences of posting derogatory or hurtful comments; posting pictures, photos, or videos that upset someone; and spreading rumors online through e-mails, blogs, social media (Facebook/Twitter/Plurk), and pictures or video clips. The items were answered using a 4-point Likert scale ranging from 0 ("never") to 3 ("all the time"). Participants who answered 1 or higher on any item were identified as selfreported victims of cyberbullying. Participants who had experienced cyberbullying victimization were further asked whether cyberbullying victimization occurred during the period of studying in primary school, junior high school, or senior high school. The Cronbach's a values of the scale for measuring cyberbullying victimization due to gender nonconformity and sexual orientation were .71 and .86 , respectively.

\section{Chen Internet Addiction Scale}

We used the self-administrated Chen Internet Addiction Scale (CIAS) to assess participants' severity of problematic Internet use in the month preceding the study. The CIAS contains 26 items rated on a 4-point Likert scale with scaled scores ranging from 26 to $104{ }^{18}$. A higher total score indicates a more severe level of problematic Internet use. The internal reliability (Cronbach's $\alpha$ ) of the CIAS in the present study was .93 .

\section{Smartphone Addiction Inventory}

We used the self-administrated Smartphone Addiction Inventory (SPAI) to assess participants' severity of problematic smartphone use in the month preceding the study. The SPAI contains 26 items rated on a 4-point Likert scale with scaled scores ranging from 26 to $104^{19}$. A higher total score indicates a more severe level of problematic smartphone use. The internal reliability (Cronbach's $\alpha$ ) of the SPAI in the present study was .93.

\section{Internet and smartphone activities}

We questioned the participants regarding seven Internet and smartphone activities in which they engaged, such as online gaming, online chatting, instant messaging (e.g., MSN), searching for sexual partners online, social media (e.g., Facebook, bulletin board systems, Twitter, and Weibo), watching movies or reading novels online, and searching for information online ${ }^{6}$.

\section{Procedure and statistical analysis}

Research assistants explained the procedures and methods of completing the research questionnaires to the participants individually. The participants could request assistance with any problems they encountered in completing the questionnaires. Data analysis was performed using the SPSS 20.0 statistical software (SPSS Inc., Chicago, IL, USA). The severity levels of problematic Internet and smartphone use in early adulthood were compared between victims and nonvictims of traditional bullying as well as between victims and nonvictims of cyberbullying during childhood and adolescence by using the Student's $t$ test. 
Participants who had experienced both traditional and cyberbullying victimization were classified to have been subjected to multitype bullying victimization. Participants who had experienced only traditional or cyberbullying were classified to have experienced single-type bullying victimization. The differences in the severity levels of problematic Internet and smartphone use among victims of multitype bullying victimization, victims of single-type bullying victimization, and nonvictims were examined using an analysis of variance (ANOVA) test. The severity levels of problematic Internet and smartphone use in early adulthood were also compared among those whose experiences of being bullied occurred only in primary school (P group), those whose experiences of being bullied lasted from primary school into junior high school (P-J group), and those whose experiences of being bullied lasted from primary school into senior high school (P-J-S group) by using the ANOVA test. The association of bullying experiences in childhood and adolescence with Internet and smartphone activities in early adulthood was examined using a chi-square test. A $p$ value of .05 was used to indicate significance in all statistical tests.

\section{Results}

Relationships of bullying victimization with problematic internet and smartphone use

A total of 500 homosexual men $(n=371)$ or bisexual men $(n=129)$ participated in this study. Their mean age was 22.9 years (standard deviation: 1.6 years, range: $20-25$ years). The experiences of traditional and cyber homophobic bullying and the severity levels of problematic Internet and smartphone use among participants are provided in Table 1. In total, 190 (38\%) and 201 (40.2\%) participants reported experiencing traditional and cyber homophobic bullying during childhood and adolescence, respectively. Of the 282 participants who had experienced traditional or cyber homophobic bullying, 199 (70.6\%) perceived homophobic bullying victimization since primary school.

Differences in problematic Internet and smartphone use in early adulthood between victims and nonvictims of traditional and cyberbullying in childhood and adolescence are provided in Table 2 . The results indicated that victims of traditional bullying had more severe problematic Internet use $(p=.013)$ and problematic smartphone use $(p=.005)$ than nonvictims of traditional bullying. Moreover, victims of cyberbullying had more severe problematic Internet use $(p=.015)$ and problematic smartphone use $(p=.001)$ than nonvictims of cyberbullying.

\section{Effects of multi-type and prolonged bullying victimization on problematic internet and smartphone use}

The differences in problematic Internet and smartphone use among victims of multitype bullying victimization, victims of single-type bullying victimization, and nonvictims of bullying victimization were examined. As presented in Table 2, victims of multitype bullying had more severe problematic Internet use than victims of

Table 1. Personal data, bullying victimization, and the severity of problematic internet and smartphone use of participants $(N=500)$

\begin{tabular}{|l|c|c|c|}
\hline & $\mathrm{n}(\%)$ & Mean (SD) & Range \\
\hline $\begin{array}{l}\text { Age (years) } \\
\text { Age of identification of sexual orientation (years) }\end{array}$ & & $22.9(1.6)$ & $13.8(3.6)$ \\
\hline Sexual orientation & & & \\
\hline \multicolumn{1}{|c|}{ Bisexuality } & $129(25.8)$ & & \\
\hline Homosexuality & $371(74.2)$ & & \\
\hline Victims of traditional bullying & $190(38)$ & & \\
\hline Victims of cyber-bullying & $201(40.2)$ & & \\
\hline Problematic internet use on the CIAS & & $58.3(14.2)$ & $26-103$ \\
\hline Problematic smartphone use on the SPAI & & $62.2(14.2)$ & $26-100$ \\
\hline
\end{tabular}

CIAS: Chen Internet Addiction Scale; STAl: Smartphone Addiction Inventory.

Table 2. Differences in the severities of problematic internet and smartphone use between victims and non-victims of traditional bullying and cyber bullying $(N=500)$

\begin{tabular}{|c|c|c|c|c|c|c|c|c|}
\hline & \multicolumn{4}{|c|}{ Problematic internet use on the CIAS } & \multicolumn{4}{|c|}{ Problematic smartphone use on the SPAI } \\
\hline & Mean (SD) & tor $F$ & $p$ & Poc hoc & Mean (SD) & tor $F$ & $p$ & Poc hoc \\
\hline \multicolumn{9}{|l|}{ Victims of traditional bullying } \\
\hline No $(n=310)$ & $57.1(13.7)$ & -2.497 & .013 & & $60.8(13.8)$ & -2.798 & .005 & \\
\hline Yes $(n=190)$ & $60.3(14.7)$ & & & & $64.4(14.6)$ & & & \\
\hline \multicolumn{9}{|l|}{ Victims of cyber-bullying } \\
\hline No $(n=299)$ & $57.0(14.2)$ & -2.444 & .015 & & $60.4(14.0)$ & -3.353 & .001 & \\
\hline Yes $(n=201)$ & $60.2(14.0)$ & & & & $64.7(14.0)$ & & & \\
\hline \multicolumn{9}{|l|}{ Types of victimization } \\
\hline Non-victims (NV) $(n=218)$ & $56.5(14.0)$ & 5.031 & .007 & $\mathrm{MV}>\mathrm{SV}, \mathrm{NV}$ & $59.6(13.9)$ & 7.590 & .001 & MV, SV > NV \\
\hline Victims of single-type bullying (SV) $(n=173)$ & $58.3(13.9)$ & & & & 63.2 (13.6) & & & \\
\hline Victims of multi-type bullying (MV) $(n=109)$ & $61.8(14.5)$ & & & & $65.7(14.8)$ & & & \\
\hline \multicolumn{9}{|l|}{ Time of bullying victimization } \\
\hline $\begin{array}{l}\text { Being bullied only at primary school } \\
(\mathrm{P})(n=33)\end{array}$ & $50.2(15.2)$ & 7.283 & .001 & P-J-S, P-J >P & $60.0(16.9)$ & 3.485 & .033 & P-J-S > P-J, P \\
\hline $\begin{array}{l}\text { Bullying lasting into junior high school } \\
\text { (P-J) }(n=87)\end{array}$ & $59.1(12.6)$ & & & & $61.4(13.1)$ & & & \\
\hline $\begin{array}{l}\text { Bullying lasting into senior high school } \\
\text { (P-J-S) }(n=79)\end{array}$ & $60.8(14.5)$ & & & & $66.2(13.3)$ & & & \\
\hline
\end{tabular}

CIAS: Chen Internet Addiction Scale; STAI: Smartphone Addiction Inventory. 
single-type bullying, whereas no difference existed in the severity of problematic smartphone use between victims of multitype and single-type bullying.

The severity levels of problematic Internet and smartphone use in early adulthood were compared among those whose experiences of being bullied occurred only in primary school (P group, $n=$ 33 ), those whose experiences of being bullied lasted from primary school into junior high school (P-J group, $n=87$ ), and those whose experiences of being bullied lasted from primary school into senior high school (P-J-S group, $n=79$ ). As presented in Table 2, the P-J-S and P-J groups ad more severe problematic Internet use in early adulthood than the P group, whereas the P-J-S group had more severe problematic smartphone use than the P-J and P groups.

\section{Association of bullying experiences with internet and smartphone activities}

The results of examining the association of bullying experiences in childhood and adolescence with Internet and smartphone activities in early adulthood are depicted in Table 3, demonstrating that victims of traditional bullying were more likely to watch movies or read novels online than nonvictims of traditional bullying $(p=.012)$. Moreover, victims of cyberbullying were more likely to use social media than nonvictims of cyberbullying $(p=.004)$.

\section{Discussion}

This study is one of the first to examine the association of homophobic bullying victimization in childhood and adolescence with problematic Internet and smartphone use in early adulthood among sexual minority individuals. Although this study did not examine how the significant association between homophobic bullying victimization and problematic Internet and smartphone use develops, minority stress hypothesis ${ }^{3,9}$, psychological mediation hypothesis $^{12,13}$, and ecological system hypothesis 15,20 have provided the fundaments to understanding the vulnerabilities of sexual minority groups to problematic Internet and smartphone use. Many sexual minority individuals live in hostile social environments full of stigma, prejudice, and discrimination. Homophobic bullying is a harmful experience that may result in victims having vivid and lasting memories of such experiences and hinder them from developing face-to-face social relationships and positive self-concepts. Additionally, homophobic bullying can evoke negative emotions in victims. The Internet may provide sexual minority individuals with anonymous and convenient environments to develop interpersonal relationships that can reduce feelings of loneliness and negative emotions ${ }^{5}$. Research has demonstrated that LGBT youths might feel supported and safe on the Internet and make more online friends than non-LGBT youths ${ }^{21,22}$. Research also revealed that LGBT youths perceived online social support to be more beneficial and safer than in-person peer relationships, although only in-person peer relationships could protect them from online and in-person bullying victimization and in-person sexual bullying ${ }^{23}$. However, Internet and smartphone use has a reinforcing effect that increases the craving for further use to relieve negative emotions ${ }^{5}$, which may partially account for problematic Internet and smartphone use among sexual minority individuals who experience homophobic bullying. Billieux et al. proposed a model of reassurance-seeking behavior, in which the negative reinforcement of problematic smartphone use may further aggravate low self-esteem, loneliness, depression, and anxiety ${ }^{24}$. The results of the present study support that homophobic bullying, whether in the traditional or online form, in childhood and adolescence must be prevented and that early detection is necessary for intervention to reduce the risk of LGBTQ youths developing problematic Internet and smartphone use.

Although the present study supported the relationship of homophobic bullying victimization in childhood and adolescence with problematic Internet and smartphone use in early adulthood among gays and bisexual men, we could not make the conclusion on the causal relationship because we did not measure the Internet and smartphone use in childhood and adolescence. Research in nonsexual minority population also found the significant association between bullying involvement and problematic Internet use. For example, a cross-sectional study found that problematic Internet use was significantly associated with both traditional bullying and cyberbullying victimization in a nationally representative sample of Hungarian adolescents ${ }^{25}$. However, other studies have supported the association between problematic Internet use and cyberbullying perpetration. For example, the cross-sectional studies have found the significant association between problematic Internet use and cyberbullying perpetration among Korean children and adolescents in community ${ }^{26}$ and among male adolescents with attentiondeficit/hyperactivity disorder in Taiwan ${ }^{27}$. A longitudinal study on adolescents in Spain found that problematic Internet use predicted an increase in cyberbullying perpetration ${ }^{28}$. The results indicate that the significant relationship between bullying involvement and

Table 3. Association of bullying experiences with internet and smartphone activities

\begin{tabular}{|c|c|c|c|c|c|c|c|c|c|c|c|c|}
\hline & \multicolumn{3}{|c|}{ Online gaming } & \multicolumn{3}{|c|}{ Online chatting } & \multicolumn{3}{|c|}{ Instant messaging } & \multicolumn{3}{|c|}{ Online searching for sex partners } \\
\hline & No & \begin{tabular}{|l|} 
Yes \\
\end{tabular} & $\chi^{2}$ & No & Yes & $\chi^{2}$ & No & Yes & $\chi^{2}$ & No & Yes & $\chi^{2}$ \\
\hline \multicolumn{13}{|c|}{ Victims of traditional bullying } \\
\hline № $(n=310)$ & 174() & 136 & 3.628 & 229 & 81 & 1.135 & 159 & 151 & 2.025 & 293 & 17 & 2.881 \\
\hline Yes $(n=190)$ & 90() & 100 & & 132 & 58 & & 85 & 105 & & 172 & 18 & \\
\hline \multicolumn{13}{|c|}{ Victims of cyber-bullying } \\
\hline № $(n=299)$ & 156 & 143 & .117 & 216 & 83 & .001 & 137 & 162 & 2.645 & 275 & 24 & 1.204 \\
\hline \multirow[t]{3}{*}{ Yes $(n=201)$} & 108 & 93 & & 145 & 56 & & 107 & 94 & & 190 & 11 & \\
\hline & \multicolumn{3}{|c|}{ Social media } & \multicolumn{3}{|c|}{$\begin{array}{l}\text { Online watching movies or } \\
\text { reading novels }\end{array}$} & \multicolumn{3}{|c|}{$\begin{array}{c}\text { Online surfing without a } \\
\text { purpose }\end{array}$} & & & \\
\hline & No & Yes & $\chi^{2}$ & No & Yes & $\chi^{2}$ & No & Yes & $\chi^{2}$ & & & \\
\hline \multicolumn{10}{|c|}{ Victims of traditional bullying } & & & \\
\hline No $(n=310)$ & 44 & 266 & 1.419 & $185(59.7)$ & $125(40.3)$ & $6.041^{*}$ & $105(33.9)$ & $205(66.1)$ & .280 & & & \\
\hline Yes $(n=190)$ & 20 & 170 & & $92(48.4)$ & $98(51.6)$ & & $60(31.6)$ & $130(68.4)$ & & & & \\
\hline \multicolumn{10}{|c|}{ Victims of cyber-bullying } & & & \\
\hline № $(n=299)$ & $48(16.1)$ & $251(83.9)$ & $7.054^{* *}$ & 163 & 136 & .236 & 97 & 202 & 105 & & & \\
\hline Yes $(n=201)$ & $16(8.0)$ & $185(92.0)$ & & 114 & 87 & & 68 & 133 & & & & \\
\hline
\end{tabular}

\footnotetext{
$*: p<.05 ; * *: p<.01$.
} 
problematic Internet use may occur not only in sexual minority but also in non-sexual minority population. However, it warrants further study to examine whether there are differences in the developmental processes of the relationship between sexual minority and non-sexual minority population.

The present study revealed that victims of both traditional and cyber homophobic bullying (multitype bullying) had more severe problematic Internet use than victims of only traditional or cyber homophobic bullying (single-type bullying). The experience of both traditional and cyber homophobic bullying indicates comprehensive and persistent social difficulties, which may marginalize victims and increase their feelings of loneliness and helplessness. Research indicated that multiple marginalization indicators interact synergistically and therefore degrade the health status of a population ${ }^{15}$. Victims of multitype homophobic bullying may perceive a greater need to search for emotional and social support from the Internet than those experiencing single-type homophobic bullying; therefore, the severity of problematic Internet use increases. However, no difference in the severity of problematic smartphone use was noted between victims of multitype and single-type homophobic bullying. Further study is required to examine why multitype homophobic bullying victimization has a different association with problematic smartphone use than with problematic Internet use.

In the present study, $70.6 \%$ of victims were bullied since primary school. Compared with those who were bullied at only primary school, sexual minority youths who experienced homophobic bullying persistently from primary to high school, especially to senior high school, developed more severe problematic Internet and smartphone use. Research reported that persistent exposure to bullying is associated with mental health complaints and poor school performance ${ }^{29}$, which may increase the appeal of the Internet and smartphones in victims of prolonged bullying and the risk of problematic Internet and smartphone use. The results of the present study support the conclusion that sexual minority individuals who experienced multitype and prolonged homophobic bullying in childhood and adolescence should be the targets of prevention and intervention programs for problematic Internet and smartphone use.

The present study revealed that victims of traditional homophobic bullying were more likely to engage in watching movies or reading novels online than nonvictims, in addition to showing that victims of cyber homophobic bullying were more likely to use social media than nonvictims. Watching movies and reading novels online may provide victims of traditional homophobic bullying with activities in which the victims can relax and have fun and do not have to interact with others, thus reducing the risk of being verbally or physically bullied. However, spending too much time watching movies and reading novels online may also reduce the victims' opportunities to have face-to-face interactions with others and further reduce their social support resources in the real world. Victims of cyber homophobic bullying may spend considerable time using smartphones to reaffirm their social relationships, relieve negative emotions, and develop. However, problematic smartphone use may further aggravate low self-esteem, loneliness, depression, and anxiety ${ }^{24}$. Moreover, social media is one of major functions of smartphones, and problematic smartphone use also increases the risk of cyberbullying.

This study has several limitations. First, this study obtained data on participants' homophobic bullying victimization; therefore, recall bias might have been introduced. However, victims of bullying may have strong emotional reactions to such events and may develop vivid and lasting memories of such experiences, thereby reducing the possibility of recall bias ${ }^{30}$. Second, the study data were exclusively self-reported. Therefore, the use of only a single data source may have influenced our findings and resulted in shared-method variances. Third, we did not evaluate participants' levels of problematic Internet and smartphone use in childhood and adolescence. Whether problematic Internet use and smartphone use persisted from childhood to early adulthood and interfered with their relationships with bullying victimization warrants further investigation.

\section{Conclusion}

Because of the positive association of homophobic bullying victimization in childhood and adolescence with problematic Internet and smartphone use in early adulthood, early prevention and intervention for homophobic bullying is required to reduce problematic Internet and smartphone use in early adulthood among gay and bisexual men. Sexual minority individuals who experienced multitype and prolonged homophobic bullying in childhood and adolescence should be the targets of prevention and intervention programs for problematic Internet and smartphone use.

\section{Acknowledgment}

This study was supported by the Ministry of Science and Technology, Taiwan, R.O.C. (grant no. MOST 104-2314-B-037-024-MY3) and the Kaohsiung Medical University Hospital (grant nos. KMUH104-4R60, KMUH105-5R59 and KMUH106-6R67).

\section{Competing interests}

None declared.

\section{Ethical approval}

This study was approved by the Institutional Review Board of Kaohsiung Medical University (KMUHIRB-F(I)-20150026).

\section{References}

1. Marshal MP, Dietz LJ, Friedman MS, Stall R, Smith HA, McGinley $\mathrm{J}$, et al. Suicidality and depression disparities between sexual minority and heterosexual youth: a meta-analytic review. J Adolesc Health. 2011;49(2):115-23.

2. Sandfort TG, Melendez RM, Diaz RM. Gender nonconformity, homophobia, and mental distress in latino gay and bisexual men. J Sex Res. 2007;44(2):181-9.

3. Birkett M, Newcomb ME, Mustanski B. Does it get better? A longitudinal analysis of psychological distress and victimization in lesbian, gay, bisexual, transgender, and questioning youth. J Adolesc health. 2015;56(3):280-5.

4. Choi SW, Kim DJ, Choi JS, Ahn H, Choi EJ, Song WY, et al. Comparison of risk and protective factors associated with smartphone addiction and Internet addiction. J of Behav Addic. 2015;4(4):308-14.

5. Elhai JD, Dvorak RD, Levine JC, Hall BJ. Problematic smartphone use: A conceptual overview and systematic review of relations with anxiety and depression psychopathology. J Affect Disord. 2017;207:251-9.

6. Lin IH, Ko CH, Chang YP, Liu TL, Wang PW, Lin HC, et al. The association between suicidality and Internet addiction and activities in Taiwanese adolescents. Compr Psychiatry. 2014;55(3):504-10.

7. Mok JY, Choi SW, Kim DJ, Choi JS, Lee J, Ahn H, et al. Latent class analysis on internet and smartphone addiction in college students. Neuropsychiatr Dis Treat. 2014;10:817-28.

8. Burton CM, Marshal MP, Chisolm DJ, Sucato GS, Friedman MS. Sexual minority-related victimization as a mediator of mental health disparities in sexual minority youth: a longitudinal analysis. J Youth Adolesc. 2013;42(3):394-402.

9. Meyer IH. Prejudice, social stress, and mental health in lesbian, gay, and bisexual populations: conceptual issues and research evidence. Psycho Bull. 2003;129(5):674-97.

10. Bischof-Kastner C, Kuntsche E, Wolstein J. Identifying problematic Internet users: development and validation of the Internet Motive Questionnaire for Adolescents (IMQ-A). J Med Internet Res. 2014;16(10):e230.

11. Kim NR, Hwang SS, Choi JS, Kim DJ, Demetrovics Z, Kiraly O, et al. Characteristics and Psychiatric Symptoms of Internet Gaming Disorder among Adults Using Self-Reported DSM-5 Criteria. Psychiatry Investig. 2016;13(1):58-66.

12. Martin-Storey A, Crosnoe R. Sexual minority status, peer harassment, and adolescent depression. J Adolesc. 2012;35(4):1001-11.

13. Hatzenbuehler ML. How does sexual minority stigma "get under the skin"? A psychological mediation framework. Psycho Bull. 2009;135(5):707-30. 
14. Allison SE, von Wahlde L, Shockley T, Gabbard GO. The development of the self in the era of the internet and role-playing fantasy games. Am J Psychiatry. 2006;163(3):381-5.

15. Ferlatte O, Dulai J, Hottes TS, Trussler T, Marchand R. Suicide related ideation and behavior among Canadian gay and bisexual men: a syndemic analysis. BMC public health. 2015;15:597.

16. Yen CF, Kim YS, Tang TC, Wu YY, Cheng CP. Factor structure, reliability, and validity of the Chinese version of the School Bullying Experience Questionnaire. Kaohsiung J Med Sci. 2012;28(9):500-5.

17. Yen CF, Chou WJ, Liu TL, Ko CH, Yang P, Hu HF. Cyberbullying among male adolescents with attention-deficit/hyperactivity disorder: prevalence, correlates, and association with poor mental health status. Res Dev Disabil. 2014;35(12):3543-53.

18. Chen S, Weng L, Su Y, Wu H, Yang P. Development of Chinese Internet Addiction Scale and its psychometric study. Chinese J Psychol. 2003;45(3):279-94.

19. Lin YH, Chang LR, Lee YH, Tseng HW, Kuo TB, Chen SH. Development and validation of the Smartphone Addiction Inventory (SPAI). PLoS One. 2014;9(6):e98312.

20. Hong JS, Espelage DL, Kral MJ. Understanding suicide among sexual minority youth in America: an ecological systems analysis. J Adolesc. 2011;34(5):885-94.

21. Hillier L, Harrison L. Building Realities Less Limited Than Their Own: Young People Practising Same-Sex Attraction on the Internet. Sexualities. 2007;10(1):82-100

22. Hillier L, Harrison L. Homophobia and the production of shame: young people and same sex attraction. Cult Health Sex. 2004;6(1):79-94.

23. Ybarra ML, Mitchell KJ, Palmer NA, Reisner SL. Online social support as a buffer against online and offline peer and sexual victimization among U.S. LGBT and non-LGBT youth. Child Abuse Negl. 2015;39:123-36.
24. Billieux J, Maurage P, Lopez-Fernandez O, Kuss DJ, Griffiths MD. Can disordered mobile phone use be considered a behavioral addiction? An update on current evidence and a comprehensive model for future research. Curr Addict Rep. 2015;2(2):156-62.

25. Zsila A, Orosz G, Király O, Urbán R, Ujhelyi A, Jármi É, et al. Psychoactive Substance Use and Problematic Internet Use as Predictors of Bullying and Cyberbullying Victimization. Int J Ment Health Addict. 2018;16(2):466-79.

26. Jung YE, Leventhal B, Kim YS, Park TW, Lee SH, Lee M, et al. Cyberbullying, problematic internet use, and psychopathologic symptoms among Korean youth. Yonsei Med J. 2014;55(3):826-30.

27. Yen CF, Chou WJ, Liu TL, Ko CH, Yang P, Hu HF. Cyberbullying among male adolescents with attention-deficit/hyperactivity disorder: prevalence, correlates, and association with poor mental health status. Res Dev Disabil. 2014;35(12):3543-53.

28. Gámez-Guadix M, Borrajo E, Almendros C. Risky online behaviors among adolescents: Longitudinal relations among problematic Internet use, cyberbullying perpetration, and meeting strangers online. J Behav Addict. 2016;5(1):100-7.

29. Lien L, Welander-Vatn A. Factors associated with the persistence of bullying victimization from 10th grade to 13th grade: a longitudinal study. Clin Pract Epidemiol Ment Health. 2013;9:243-50.

30. Ladd GW, Kochenderfer-Ladd B. Identifying victims of peer aggression from early to middle childhood: analysis of cross-informant data for concordance, estimation of relational adjustment, prevalence of victimization, and characteristics of identified victims. Psychol Assess. 2002;14(1):74-96. 